\title{
AVALIAÇÃO ECOTOXICOLÓGICA DO EXTRATO SOLUBILIZADO DE BAGACO DE CANA-DE-ACUÚCAR RESIDUAL VIA GERMINAÇÃO DE SEMENTES DE ALFACE (LACTUCA SATIVA L.)
}

\author{
Sérgio Thode Filho ${ }^{1}$, Cintia Patrícia Santos da Paixão², Fabíola da Silveira \\ Maranhão ${ }^{3}$, Heider Alves Franco ${ }^{4}$
}

\begin{abstract}
Resumo: Processar uma tonelada de cana-de-açúcar produz em média $250 \mathrm{~kg}$ de bagaço como subproduto. Nos centros urbanos o consumo está atrelado ao descarte inadequado, não sendo possível, estimar, o volume de subproduto gerado. Sendo assim, objetivou-se estimar o nível de fitotoxicidade do extrato solubilizado do bagaço da cana residual $(B C R)$ sobre a germinação de sementes de alface (Lactuca sativa L.). Adotou-se o delineamento inteiramente casualizado com seis tratamentos no grupo teste (BCR + água destilada = 4,0ml): T1 $(0,1 \mathrm{~mL} \mathrm{BCR}+3,99 \mathrm{~mL}), T 2(0,4 \mathrm{~mL} \mathrm{BCR}+3,6 \mathrm{~mL}), T 3(0,7 \mathrm{~mL} \mathrm{BCR}+3,3 \mathrm{~mL}), \mathrm{T4}$ $(1,0 \mathrm{~mL} \mathrm{BCR}+3,0 \mathrm{~mL}), T 5(2,0 \mathrm{~mL} B C R+2,0 \mathrm{~mL}), T 6(3,0 \mathrm{~mL} \mathrm{BCR}+1,0 \mathrm{~mL}$ de água destilada) e um grupo controle (água destilada), todos em triplicata. Pequenas doses do BCR apresentaram efeito fitotóxico sobre a alface. A CL50 calculada para a alface (Lactuca sativa L.) foi de 1,78 $\mathrm{mL}$. Haja vista que a espécie em estudo é um organismo-teste padrão, é possível estimar que o BCR apresenta potencial de contaminação sobre outras espécies vegetais, logo, a fim de mitigar esse efeito, deve-se dar atenção especial ao descarte desse resíduo.
\end{abstract}

Palavras-chave: Bagaço de cana. Fitotoxicidade. Germinação. Concentração Letal.

\section{Introdução}

O Brasil é o maior produtor de açúcar do mundo, e se destaca na produção de biocombustível etanol como alternativa energética. Estima-se que a produção da safra 2017/2018 deve chegar a 635,59 milhões de toneladas no país (BRASIL, 2018).

O processamento de uma tonelada de cana, para qualquer finalidade, produz em média duzentos e cinquenta quilos de bagaço como subproduto (ALVES, 2006). Entre 60 e $90 \%$ deste material é utilizado pela própria indústria sucroalcooleira como combustível para geração de energia e calor, que atende a $98 \%$ de sua demanda energética (FAPESP 1998; SOUZA; AZEVEDO, 2006), entretanto, existe ainda um excedente que gera problemas ambientais e de estocagem (SUN et al., 2004).

O bagaço de cana-de-açúcar in natura é definido como resíduo dos colmos da cana-de-açúcar, resultado da extração máxima do conteúdo celular rico em açúcares solúveis. Sendo assim, esse resíduo reúne fragmentos grosseiros da parede celular e conteúdo celular não extraído na moagem da cana-de-açúcar, cujo componente principal, aproximadamente 2 a $3 \%$, é representado pelo açúcar não extraído durante o processo de moagem e ainda alto teor de componentes da parede celular (carboidratos estruturais), em torno de 70 a $85 \%$, dos quais a celulose é o principal (44 a $50 \%$ ), seguida da hemicelulose (24 a $30 \%$ ) e da lignina (10 a 20\%) (MEDEIROS, 1992).

Tem-se ainda em termos de constituição do resíduo que o mesmo possui três frações principais (celulose, hemicelulose e lignina), as quais, juntas, perfazem mais de $90 \%$ da massa total (PANDEY et al., 2000). A xilose é o principal carboidrato encontrado na fração hemicelulósica, representando cerca de $80 \%$ dos açúcares totais (AGUILAR et al., 2002; MOSIER et al., 2005). Em geral, o teor de cinzas encontrado no bagaço é pequeno (PANDEY et al. 2000). Por outro lado, os

\footnotetext{
1E-mail: sergio.thode@ifrj.edu.br

Instituto Federal de Educação, Ciência e Tecnologia do Rio de janeiro (IFRJ) - Núcleo de Monitoramento Ambiental (NUMA) - Laboratório Multidisciplinar de Gerenciamento de Resíduos (LMGR)

²E-mail: cintia.patricia.santos@gmail.com

3E-mail: fabiola.smaa@gmail.com

${ }^{4}$ E-mail: heider.franco@ifri.edu.br
} 


\section{REA - Revista de estudos ambientais (Online) v.21, n. 1, p.46-55, jan./jun. 2019}

extrativos, como graxas, gomas, amidos, alcaloides, resinas e óleos essenciais, podem representar acima de $5 \%$ da massa total. Os extrativos são constituídos por uma grande variedade de compostos orgânicos e podem ser extraídos com solventes orgânicos ou aquosos (FENGEL; WEGENER, 1989).

A utilização da cana-de-açúcar ocorre tanto em termos de produção de açúcar quanto de etanol, contudo existe um hábito comum de consumo que é o caldo de cana também chamado de garapa, uma bebida opaca, de coloração variável de pardo a verde escura, e viscosa muito apreciada na forma in natura e/ou com adição de limão e gelo. Trata-se de uma bebida de elevado valor nutritivo, não alcoólica e muito consumida principalmente em regiões de clima quente, por ser refrescante (MOLINA et al., 2007a; MOLINA et al., 2007b). O processo de obtenção da bebida ocorre por meio da moagem da canade-açúcar que também gera como resíduo, o bagaço.

Diversos trabalhos têm buscado alternativas para a utilização deste subproduto, citando-se como exemplos 0 preparo de rações animais, a fabricação de papel e celulose, e a produção de insumos com maior valor agregado por meio de processos fermentativos (SILVA et al., 2002; CARVALHO et al., 2006; SILVA et al., 2007; MURTA et al., 2011; DUTRA et al., 2013).

Nesse sentido, ensaios de ecotoxicidade podem contribuir para a identificação do potencial de contaminação deste resíduo, principalmente quando 0 mesmo for descartado incorretamente. Diante disso, o presente trabalho objetivou estimar o nível de fitotoxicidade a partir da aplicação do extrato solubilizado do bagaço da cana residual (BCR) sobre a germinação de sementes de alface (Lactuca sativa L.).

\section{Metodologia}

\subsection{Preparo e obtenção do extrato}

As amostras do BCR foram coletadas em uma feira livre próximo ao IFRJ-CDUC, conforme a metodologia recomendada pela NBR 10.007 (ABNT, 2004a). O material foi coletado em uma pilha, as 10 horas da manhã e o mesmo havia sido beneficiado a menos de 2 horas. Em virtude da homogeneidade quanto ao aspecto físico do material residual, foram retiradas quatro amostras simples de topo, meio e base no entorno da pilha/monte do resíduo. Essas foram misturadas a fim de se obter uma amostra composta. O material sólido da amostra composta foi fracionado em pedaços para obtenção de fragmentos uniformes, dando origem a uma amostra homogênea. A partir dessa, iniciou-se o processo de obtenção do extrato solubilizado do BCR.

O extrato solubilizado foi preparado de acordo com metodologia recomendada pela NBR 10.006 (ABNT, 2004b). Para preparar 0 extrato solubilizado, foram transferidos $250 \mathrm{~g}$ de BCR picados com comprimento de $5 \mathrm{~cm}$ para um recipiente de vidro hermético contendo $1,0 \mathrm{~L}$ de água destilada. $\mathrm{O}$ material (água $+\mathrm{BCR}$ ) foi agitado durante $5 \mathrm{~min}$ em um agitador magnético (Fisatom 752) à temperatura ambiente $(25 \pm 1 \stackrel{\circ}{\circ})$. Na sequência, 0 recipiente foi fechado e 0 material permaneceu em repouso durante 7 dias. Após esse período ocorreu a filtração através de uma membrana filtrante de 0,45 $\mu \mathrm{m}$.

\subsection{Análise físico-química}

Os parâmetros físico-químicos: $\mathrm{pH}$, condutividade, TDS (sólidos dissolvidos totais) e salinidade foram determinados no extrato solubilizado de BCR utilizando uma sonda multi parâmetros (COMBO 5 - AKSO).

\subsection{Amostra de sementes}

Foram adquiridas sementes de alface crespa (Lactuca sativa L.) da marca ISLA PAK com 99,7\% de pureza, 98\% de germinação e validade até agosto/19. As mesmas foram utilizadas diretamente, sem execução de nenhum procedimento prévio de desinfecção ou quebra de dormência.

\subsection{Teste de fitotoxicidade}

Testes de toxicidade sobre germinação e desenvolvimento de radículas usando sementes de alface (Lactuca sativa L.) foram realizados para avaliar os efeitos letais, a partir da inibição na germinação de sementes e os efeitos subletais via desenvolvimento radicular (SOBRERO; RONCO, 2004; OECD, 2003).

Adotou-se 0 delineamento experimental inteiramente casualizado 
composto de seis tratamentos para o grupo teste e um grupo controle. Para todos os tratamentos foram utilizadas 3 repetições (7x3). O croqui proposto para a disposição dos tratamentos na incubadora encontra-se na tabela 1. Os tratamentos experimentados no grupo teste foram: T1 $(0,1 \mathrm{~mL}$ do extrato solubilizado BCR + 3,99 $\mathrm{mL}$ de água destilada), T2 (0,4 $\mathrm{mL}$ do extrato solubilizado $\mathrm{BCR}+3,6 \mathrm{~mL}$ de água destilada), T3 $(0,7$
$\mathrm{mL}$ do extrato solubilizado $\mathrm{BCR}+3,3 \mathrm{~mL}$ de água destilada), T4 (1,0 mL do extrato solubilizado BCR $+3,0 \mathrm{~mL}$ de água destilada), T5 (2,0 mL do extrato solubilizado $\mathrm{BCR}+2,0 \mathrm{~mL}$ de água destilada), T6 (3,0 $\mathrm{mL}$ do extrato solubilizado $\mathrm{BCR}+1,0 \mathrm{~mL}$ de água destilada). O TC (grupo controle) era composto apenas de $4,0 \mathrm{~mL}$ de água destilada.

Figura 1 - Croqui com a disposição dos tratamentos em câmara de germinação

\begin{tabular}{|lllllll|}
\hline T2.1 & TC.3 & T6.2 & T4.3 & T1.1 & T3.2 & T5.1 \\
T6.3 & T4.1 & TC.1 & T2.2 & T4.2 & T5.2 & TC.2 \\
T1.2 & T5.3 & T3.1 & T6.1 & T1.3 & T2.3 & T3.3 \\
\hline
\end{tabular}

Fonte: Autores (2019)

$\mathrm{Na}$ condução do estudo, 10 sementes de alface (Lactuca sativa L.) foram alocadas em posições diametralmente iguais, sobre substrato papel de filtro qualitativo (porosidade $1 \mu \mathrm{m}$ ) em placa de Petri $(9,5 \mathrm{~cm}$ de diâmetro) que posteriormente foram umedecidas com volume equivalente aos tratamentos definidos. Para garantir a umidade ao longo de todo o ensaio, as placas de Petri foram envolvidas com plástico filme transparente. A condição ambiente para o teste foi: temperatura $\left(25 \pm 1^{\circ} \mathrm{C}\right)$; fotoperíodo (12 horas de luz/12 horas de escuro) e tempo total de ensaio 120 horas (BRASIL, 2009). Essas condições foram obtidas com uso de câmara de germinação do tipo BOD da marca SOLAB modelo SL-225, onde as placas de Petri foram dispostas.

\subsection{Avaliação da fitomassa}

Ao final do período experimental, foram avaliados os seguintes parâmetros: número de sementes germinadas, comprimento das radículas e parte aérea (USEPA, 1996; OECD, 2003). O comprimento da radícula e parte aérea foi obtido com o auxílio de um paquímetro digital.

Os efeitos subletais foram determinados pela identificação da concentração do efeito não observado (CENO), que corresponde à maior concentração/dose da substância testada que não causa efeitos deletérios estatisticamente significativos sobre os organismos durante o tempo de exposição sob as condições de teste; e a menor concentração de efeito observado (CEO), que é a menor concentração/dose da substância testada que causa efeitos deletérios estatisticamente significativos sobre os organismos durante o tempo de exposição e condições de teste (RONCO; BAEZ; GRANADOS, 2004). CENO e CEO foram determinados por comparação entre a média do comprimento das radículas.

$\mathrm{O}$ cálculo da $\mathrm{CL}_{50}$ foi realizado segundo metodologia proposta por Franco et al. (2017).

\subsection{Análise estatística}

Para determinar a existência de correlação entre a germinação de sementes, o comprimento da parte aérea, das radículas e as diferentes dosagens do poluente (extrato solubilizado borra) empregou-se o coeficiente de correlação de Pearson, com determinação do índice de correlação (r) (ACHEN, 1977; ALDRICH, 1995).

Para todos os parâmetros deste estudo foram realizados 0 teste de pressuposição (teste de normalidade e teste de homogeneidade de variância). Os dados foram submetidos à análise de variância (ANOVA) e as médias foram comparadas pelo teste de Tukey a $5 \%$ de probabilidade entre as mesmas (COSTA NETO, 1977; MILLER, J.C.; MILLER, J.N., 1993), com auxílio do software BioEstat 5.0 e os gráficos apresentados foram confeccionados no software SigmaPlot 12.5 .

\section{Resultados}

A tabela 1 apresenta as propriedades físico-químicas do extrato 


\section{REA - Revista de estudos ambientais (Online) v.21, n. 1, p.46-55, jan./jun. 2019}

solubilizado BCR, bem como da água utilizada para preparação do mesmo. Podese observar que o BCR apresentou um $\mathrm{pH}$ extremamente ácido, além de grande elevação na condutividade, teor de sólidos totais dissolvidos (TDS) e salinidade.

Tabela 1 - Propriedades físico-químicas do extrato solubilizado BCR

\begin{tabular}{ccccc}
\hline Amostra & $\mathbf{p H}$ & $\begin{array}{c}\text { Condutividade } \\
(\boldsymbol{\mu S} / \mathbf{c m})\end{array}$ & $\begin{array}{c}\mathbf{S T D}^{*} \\
(\mathbf{p p m})\end{array}$ & $\begin{array}{c}\text { Salinidade } \\
(\mathbf{p p m})\end{array}$ \\
\hline Água destilada & 6.9 & 5,0 & 3,6 & 2,6 \\
Solubilizado BCR & 3.1 & 1331 & 883 & 669 \\
\hline
\end{tabular}

*Sólidos totais dissolvidos.

Fonte: Autores (2019)

O procedimento adotado para obtenção do extrato solubilizado tem por finalidade demonstrar que, uma vez em contato com a água, o resíduo não modificaria a qualidade dos padrões de potabilidade da água (ABNT, 2004b). Verifica-se que o BCR em estudo se mostrou solúvel em água e modificou as características físico-químicas da mesma.

De acordo com a NBR 10.004 (ABNT, 2004c), este resíduo é classificado como Classe II A, Não Perigoso - Não Inerte.

A análise dos valores médios do percentual de germinação em função dos diferentes tratamentos com solubilizado BCR mostrou uma diminuição na germinação conforme se aumentou a dose do extrato (Figura 2). O grupo controle apresentou $98 \%$ de germinação. Os dois primeiros tratamentos $0,1 \mathrm{~mL}$ e $0,4 \mathrm{~mL}$ apresentaram os melhores resultados (93 e $80 \%$ ). O tratamento com $0,7 \mathrm{~mL}$ apresentou uma taxa germinativa abaixo de $75 \%$ e o tratamento com $2 \mathrm{~mL} 53 \%$. O tratamento com $3 \mathrm{~mL}$ apresentou apenas 3\% de germinação das sementes. Verifica-se que a presença do solubilizado foi preponderante para a inibição do percentual de germinação. Foi observada uma relação quadrática entre o aumento da dosagem do extrato BCR e a germinação de sementes.

Figura 2 - Percentual de germinação de sementes de alface (Lactuca sativa L.) submetidas a diferentes dosagens do extrato solubilizado do BCR: (a) controle, (a) $0,1 \mathrm{~mL}$ (b) $0,4 \mathrm{~mL}$, (c) $0,7 \mathrm{~mL}$, (d) $1,0 \mathrm{~mL}$, (e) $2,0 \mathrm{~mL}$, (f) $3,0 \mathrm{~mL}$

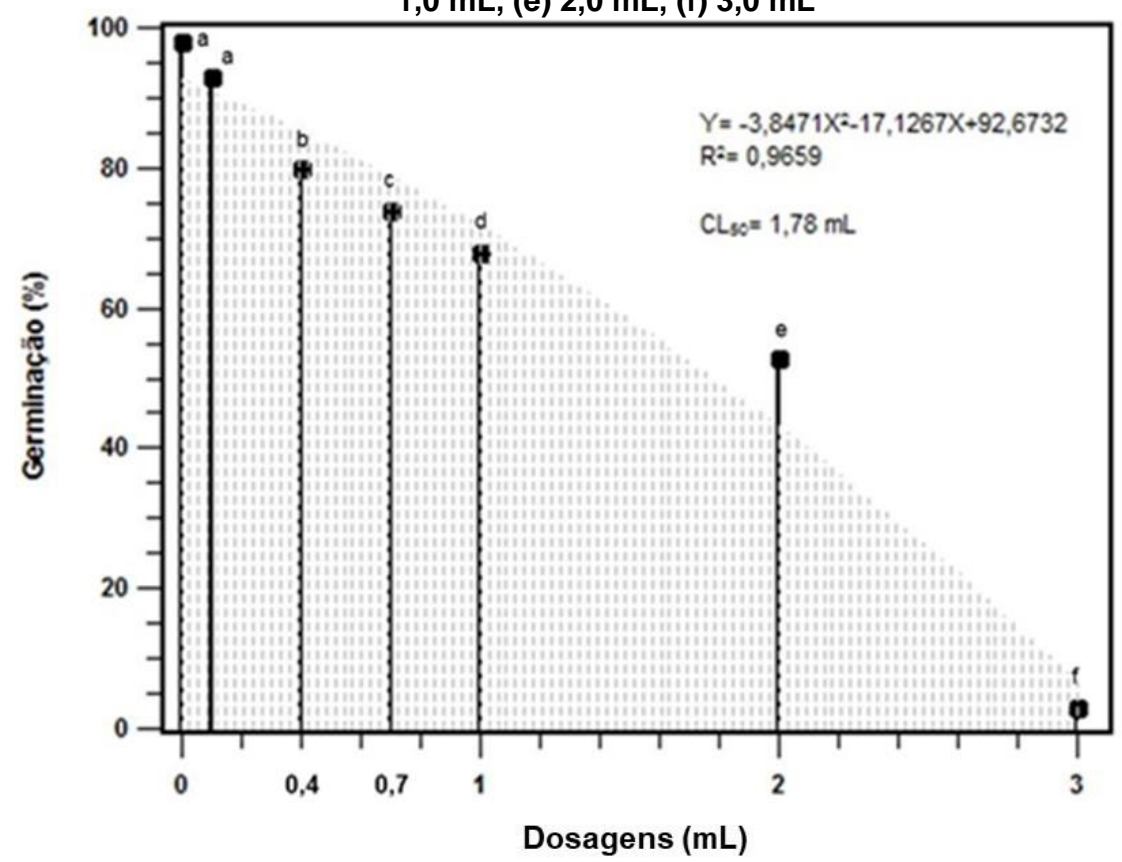

* Médias seguidas pela mesma letra minúscula não diferem estatisticamente entre si pelo teste de Tukey a $5 \%$ de probabilidade.

Fonte: Autores (2019) 


\section{REA - Revista de estudos ambientais (Online) v.21, n. 1, p.46-55, jan./jun. 2019}

A germinação é uma sequência ordenada de atividades metabólicas divididas em fases, que resulta na formação de uma plântula. A germinação é também um indicador da tolerância das plantas aos sais em estádios subsequentes do crescimento e desenvolvimento (LARCHER, 2000).

Segundo Ribeiro et al. (2009), salinidade é a situação do excesso de sais solúveis, sódio trocável ou ambos, que afeta o desenvolvimento da planta. $\mathrm{O}$ efeito mais facilmente observado do excesso de salinidade nas plantas é a redução do crescimento devido a desequilíbrios nutricionais (CAVALCANTE et al., 2011).

Para o cálculo da CL50 do teste de germinação das sementes de alface (Lactuca sativa L.) a função quadrática foi descrita por $y=-3,8471 x^{2}-17,1267 x+92,6732$ com
$R^{2}=0,9659$. Utilizando essa função e substituindo y por 50 , encontrou-se a dose de $1,78 \mathrm{~mL}$ para a $C_{50}$ referente à alface (Lactuca sativa L.).

Os valores médios do comprimento da parte aérea em função dos diferentes tratamentos com solubilizado BCR apresentaram redução no parâmetro conforme se aumentou a dose do extrato (Figura 3). Comparativamente com o grupo controle, o tratamento com $0,1 \quad \mathrm{~mL}$ apresentou uma inibição de $21 \%$. Para os tratamentos com 0,4 e $0,7 \mathrm{~mL}$ a inibição foi de $63 \%$. Já os tratamentos com 1,0, 2,0 e 3,0 $\mathrm{mL}$ apresentaram inibição de $78 \%$. Observou-se também uma relação quadrática entre o aumento da dosagem do extrato BCR e comprimento da parte aérea.

Figura 3 - Comprimento da parte aérea de sementes de alface (Lactuca sativa L.) submetida a diferentes dosagens do extrato solubilizado do BCR. (a) controle, (b) $0,1 \mathrm{~mL}$ (c) $0,4 \mathrm{~mL}$, (c) $0,7 \mathrm{~mL}$, (d) $1,0 \mathrm{~mL}$, (d) $2,0 \mathrm{~mL}$, (d) $3,0 \mathrm{~mL}$

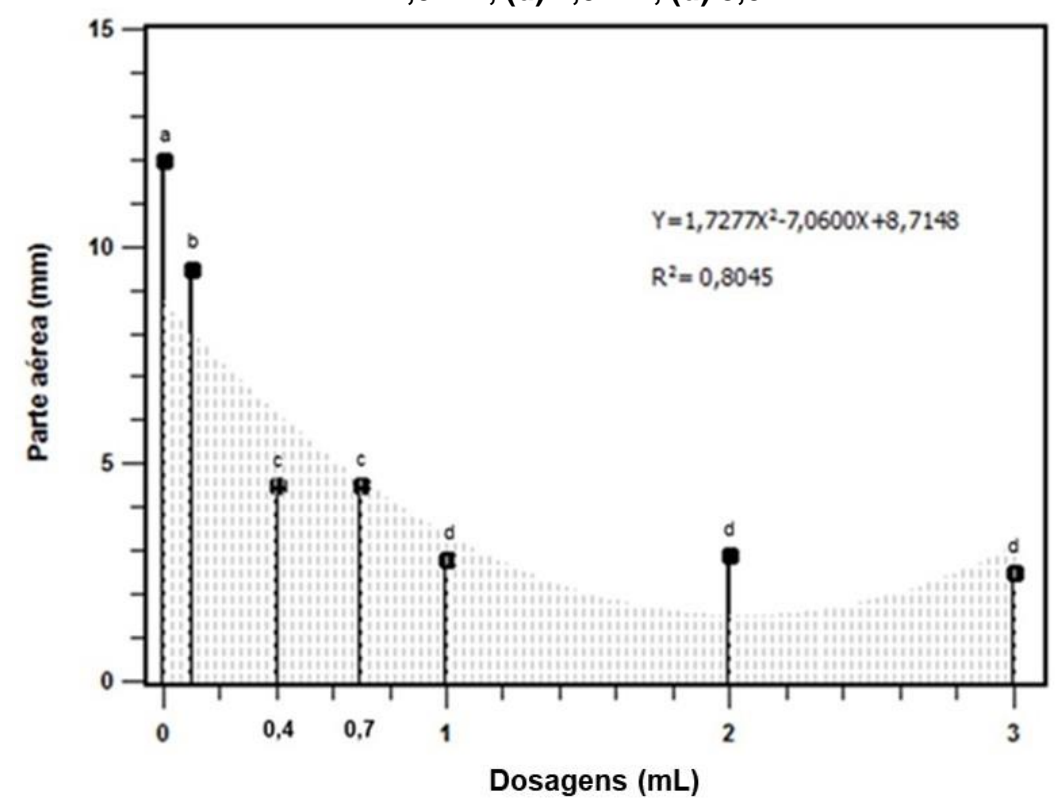

* Médias seguidas pela mesma letra minúscula não diferem estatisticamente entre si pelo teste de Tukey a $5 \%$ de probabilidade.

Fonte: Autores (2019)

O resultado médio das diferentes doses do solubilizado BCR sobre 0 comprimento das radículas estão apresentados na Figura 4. O grupo controle e o tratamento com $0,1 \mathrm{~mL}$ do $B C R$ não apresentaram diferença significativa em seu comprimento $(37 \mathrm{~mm})$. Comparativamente com o grupo controle, o tratamento com 0,4 $\mathrm{mL}$ apresentou uma inibição do crescimento da estrutura radicular de $52 \%$. O mesmo comportamento inibitório foi observado para os demais tratamentos: 0,7 e $1,0 \mathrm{~mL}(70 \%)$, $2,0 \mathrm{~mL}(89 \%)$ e $3,0 \mathrm{~mL}(97 \%)$. Observou-se uma diminuição no comprimento da radícula conforme se aumentou a dose do extrato. Semelhantemente aos outros parâmetros em estudo, observou-se uma relação quadrática entre o aumento da dosagem do extrato BCR e o comprimento da radícula. 


\section{REA - Revista de estudos ambientais (Online) v.21, n. 1, p.46-55, jan./jun. 2019}

Figura 4 - Comprimento da radícula de sementes de alface (Lactuca sativa L.) submetida a diferentes dosagens do extrato solubilizado do BCR. (a) controle, (a) $0,1 \mathrm{~mL}$ (b) $0,4 \mathrm{~mL}$, (c) $0,7 \mathrm{~mL}$, (c) $1,0 \mathrm{~mL}$, (d) $2,0 \mathrm{~mL}$, (e) $3,0 \mathrm{~mL}$

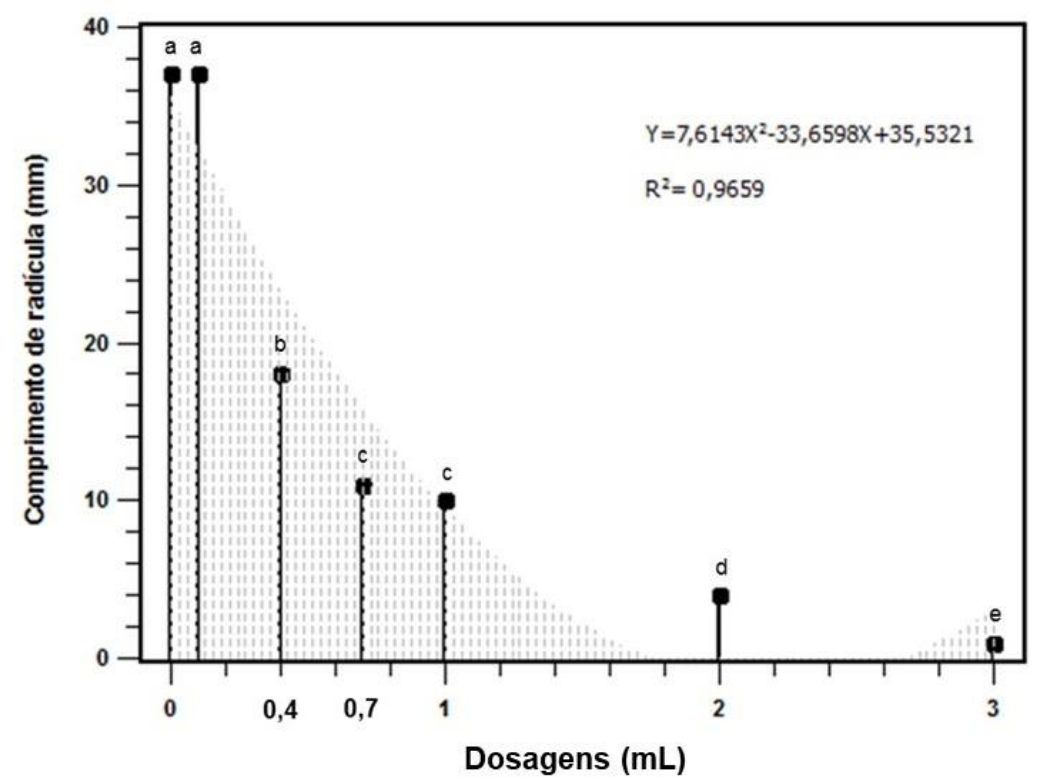

* Médias seguidas pela mesma letra minúscula não diferem estatisticamente entre si pelo teste de Tukey a $5 \%$ de probabilidade.

Fonte: Autores (2019)

A determinação da CENO estabeleceu-se no tratamento com $0,1 \mathrm{~mL}$ de extrato, sendo esta a dose que não causa efeito significativo no comprimento das radículas de alface (Lactuca sativa $\mathrm{L}$.). No entanto, a CEO ficou estabelecida no tratamento com $0,4 \mathrm{~mL}$. Sendo esta a dose que causou efeito deletério significativo. $O$ que determina uma elevada toxicidade do extrato em estudo, haja vista o comprometimento do sistema radicular em dose muito baixa.

O extrato solubilizado BCR em estudo não proporcionou benefícios morfológicos às plântulas (Figura 1, 2 e 3). Apresentou um caráter extremamente ácido e alta salinidade. O comprimento da radícula sofreu uma redução rigorosa, com visível inibição do seu crescimento ocorrendo com o aumento das doses do BCR (Figura 5).

A capacidade das plantas de obter água e nutrientes minerais do solo está relacionada à sua capacidade de desenvolver um sistema radicular extenso (TAIZ et al., 2017). Entende-se, portanto, que a inibição do crescimento provocado pela introdução do poluente em estudo, pode comprometer seriamente o desenvolvimento vegetativo desta planta, uma vez que, com o sistema radicular comprometido, a planta não é capaz de absorver os elementos essenciais para completar seu ciclo. Assim, pode-se observar que essas plântulas não poderiam sobreviver em condições de campo, uma vez que a capacidade de absorver água e nutrientes é bastante prejudicada.

Para o ensaio de germinação de sementes com diferentes tratamentos do extrato solubilizado BCR, verificou-se uma correlação negativa ( $r$ ) altamente significativa de -0.9385. A mesma correlação negativa $(r)$ foi observada para parte aérea $(-0,6238)$ e o comprimento de radículas $(-0,7438)$. Isto é, quanto maior a dosagem do solubilizado BCR, menor será o percentual de germinação, parte aérea e o comprimento das radículas atingido no teste.

Com isso, evidencia-se que a inserção do poluente tem efeito deletério sobre as características morfológicas da planta.

Considerando a constituição do bagaço de cana, estão presentes substâncias que podem ser extraídas do material vegetal, tais como ceras, álcoois, lipídeos, esteroides, ácidos graxos, hidrocarbonetos e flavonoides. Alguns desses compostos extrativos podem ser tóxicos. Basicamente, todos os flavonoides são constituídos por três anéis, onde os seus carbonos podem sofrer variações químicas, como hidroxilação, hidrogenação metilação e sulfonação, proporcionando a formação de 


\section{REA - Revista de estudos ambientais (Online) v.21, n. 1, p.46-55, jan./jun. 2019}

mais de quatro mil compostos flavonóides, que são agrupados em classes. Entre esses flavonoides destacam-se os heterosideos que são solúveis em água (GEORGIEV; ANANGA; TSOLOVA, 2014).

Figura 5 - Comprimento de radícula e parte aérea da germinacao de sementes de alface (Lactuca sativa L.) submetidas a diferentes dosagens do extrato solubilizado do BCR. (a) controle, (b) $0,1 \mathrm{~mL}$ (c) $0,4 \mathrm{~mL}$, (d) $0,7 \mathrm{~mL}$, (e) $1,0 \mathrm{~mL}$, (f) $2,0 \mathrm{~mL}$, (g) $3,0 \mathrm{~mL}$
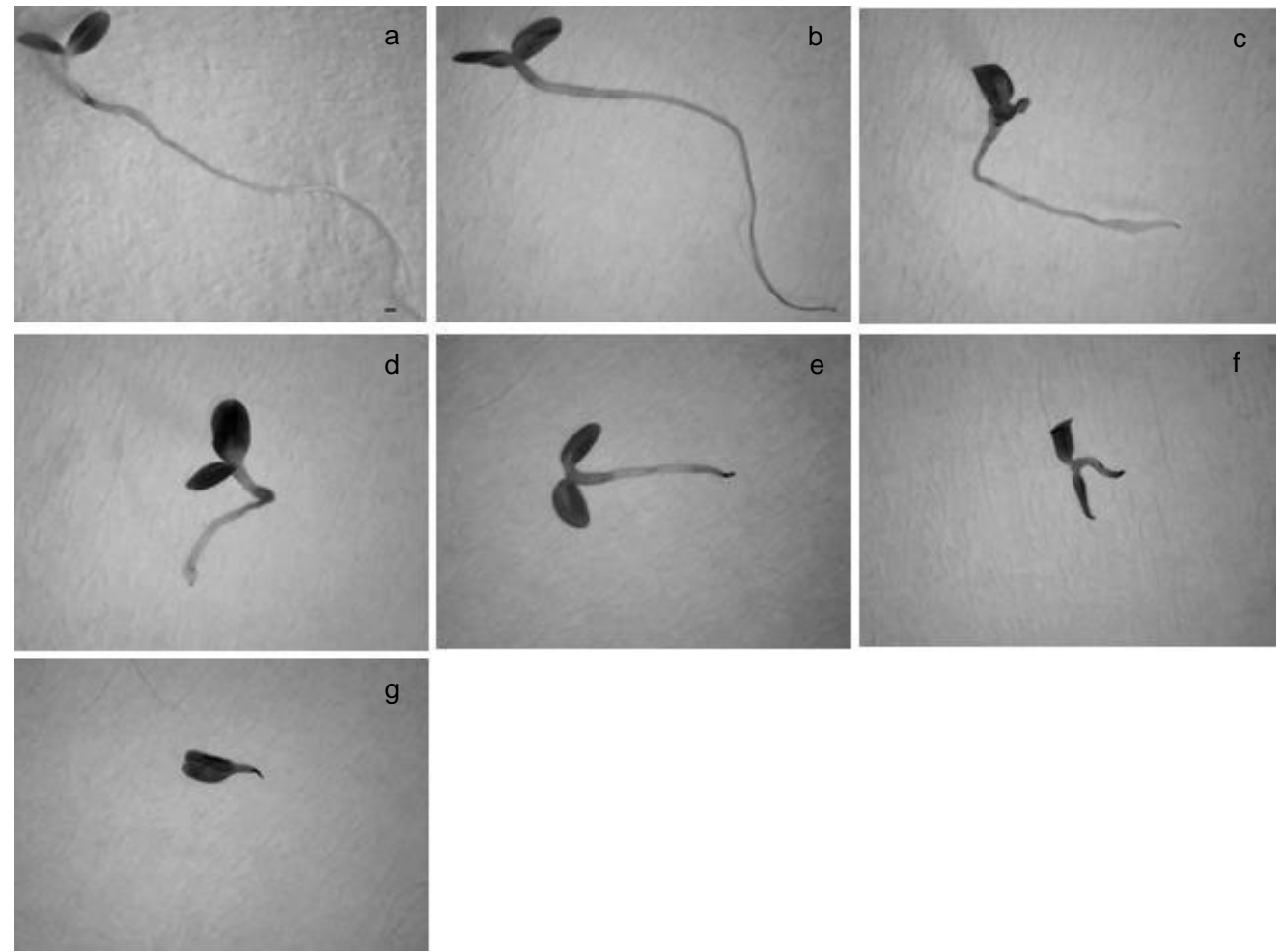

*Todas as figuras foram avaliadas com a mesma escala $(1 \mathrm{~mm})$.

Fonte: Autores (2019)

Souza et al. (1999) avaliaram o efeito inibitório dos extratos hidroalcóolicos de capim-gordura (Melinis minutiflora), capimjaraguá (Hyparrhenia rufa), capim-colonião (Panicum maximum), mucuna (Mucuna aterrima) e serrapilheira de bambu (Bambuza spp.), sobre a germinação de sementes de alface e cenoura. Os autores identificaram que todos os extratos promoveram redução na germinação das sementes, contudo, o extrato de mucuna apresentou o maior efeito inibidor em comparação, sendo que tal fato pode estar relacionado a presença de ácidos fortes fixos que foi 0 principal fator diferenciado no extrato de mucuna em relação aos demais. Sugere-se que a inibição observada tanto na germinação quanto no crescimento das raízes, pode ocorrer devido a agentes alelopáticos que afetam o desenvolvimento da radícula de forma direta ou indireta, pois existe uma vasta gama de metabólicos secundários encontrado em plantas que possuem essa característica.
No bagaço, verificam-se os metabólitos secundários fenólicos e terpernóicos. Esses agentes são encontrados predominantemente na lignina, seus compostos aromáticos, tendo fenóis, ácidos fenólicos, derivados do ácido cinâmico, cumarinas, flavonóides, catequinas, quinas e tominos. Uma gama diversa de metabólitos secundários é encontrada nas plantas, os fenólicos e terpenóides apresentam a maior parte dos compostos com atividades alelopáticas identificados (BARKOSKY; EINHELLIG; BUTLER, 2000; FUJII; HIRADATES, 2007).

Faria et al. (2009) identificaram que extratos de mucuna e milheto diminuíram o comprimento do hipocótilo e da radícula de soja e os de Pinus aumentaram esses comprimentos. $\mathrm{Em}$ feijão, $\mathrm{O}$ extrato de Pinus diminuiu o comprimento do hipocótilo e da radícula, mas os extratos de mucuna e milheto aumentaram-no. $\mathrm{O}$ extrato do milheto reduziu a percentagem e a velocidade de germinação em feijão. 


\title{
REA - Revista de estudos ambientais (Online)
} v.21, n. 1, p.46-55, jan./jun. 2019

Oliveira et al. (2014) observaram que o extrato etanólico das cascas de Pouteria ramiflora, apesar de não afetar negativamente as taxas de germinação, possui a presença de aleloquímicos que interferiram negativamente no crescimento das plântulas de alface, indicando efeito alelopático e potencial de utilização. As diferentes concentrações de 2,5 e $5,0 \%$ do extrato etanólico da parte interna da casca, prejudicaram o desenvolvimento da raiz e da parte aérea, efeito associado à presença de esteróides e triterpenos, presentes neste extrato.

Desse modo, o extrato solubilizado de BCR pode ter proporcionado a liberação de ácidos cinâmicos, que segundo Simões e Spitzer (1999) atuam indiretamente, são responsáveis pela inibição da germinação e do crescimento de plantas. Sugere-se, porém, que estudos sejam realizados com prospecção química do bagaço de cana residual a fim de identificar os metabólitos secundários existentes nos diferentes extratos e desse modo, destacar aqueles com potencial de efeito inibitório/alelopático.

\section{Conclusões}

Pequenas doses do solubilizado $\mathrm{BCR}$ causaram efeito fitotóxico à germinação das sementes e o crescimento das radículas de L. sativa.

A CL50 calculada para a alface (Lactuca sativa L.) foi de $1,78 \mathrm{~mL}$. Com isso, evidencia-se que a espécie estudada possui baixa tolerância ao poluente. Entretanto, a dose correspondente ao efeito sobre as radículas foi obtida com $0,4 \mathrm{~mL}$ (CEO), inferindo um caráter agressivo do extrato testado, sob a ótica de efeitos subletais.

Infere-se que no presente estudo, a inibição da germinação das sementes de alface e crescimento das radículas, pode ocorrer devido à presença de agentes alelopáticos advindos do bagaço de cana residual.

Os resultados obtidos no presente estudo indicam que os diferentes tratamentos com solubilizado BCR contribuíram para um decréscimo acentuado nos parâmetros físicos avaliados a partir da germinação de alface (Lactuca sativa L.), principalmente devido a severa acidez do $\mathrm{pH}$ e elevada salinidade. Haja vista que a espécie em estudo é um organismo-teste padrão, é possível estimar que o BCR apresenta potencial de contaminação sobre outras espécies vegetais, desse modo especial atenção deve ser dada ao descarte do resíduo como forma de mitigar esse efeito potencial.

\section{Ecotoxicological evaluation of solubilized extract of residual sugarcane bagasse in germination of lettuce seeds (Lactuca sativa L.)}

\begin{abstract}
Processing a sugar cane tonne produces on average $250 \mathrm{~kg}$ of bagasse as a by-product. In urban centers, the consumption of sugarcane is linked to inadequate disposal, being not possible to estimate the volume generated. This study aimed to estimate the phytotoxicity level of the solubilized sugarcane bagasse extract (BCR) on the germination of lettuce seeds (Lactuca sativa L.). A completely randomized design with six treatments in the test group $(B C R+$ distilled water $=4.0 \mathrm{~mL})$ was used: $T 1(0.1 \mathrm{~mL} B C R+3.99 \mathrm{~mL}), T 2$ $(0.4 \mathrm{~mL} \mathrm{BCR}+3.6 \mathrm{~mL}), T 3(0.7 \mathrm{~mL} B C R+3.3 \mathrm{~mL}), T 4(1.0 \mathrm{~mL} B C R+3.0 \mathrm{~mL}), \mathrm{T5}(2.0 \mathrm{~mL} B C R+2.0 \mathrm{~mL})$, T6 (3.0 mL BCR + $1.0 \mathrm{~mL}$ of distilled water) and a control group (distilled water), all in triplicate. Small doses of BCR showed a phytotoxic effect on Lettuce. The LC50 calculated for lettuce (Lactuca sativa L.) was 1.78 $\mathrm{mL}$. Since the species under study is a standard test organism, it is possible to estimate that the BCR has potential for contamination other plant species, so in order to mitigate this effect, special attention should be given to this waste disposal.
\end{abstract}

Keywords: Sugarcane bagasse; Phytotoxicity; Germination; Lethal Concentration.

\section{Referências}

ACHEN C.H. Measuring Representation: Perils of the Correlation Coefficient. American Journal of Political Science, v. 21, n. 4, p. 805-815, 1977.
AGUILAR, R.; RAMÍREZ, J.A.; GARROTE, G.; VÁZQUEZ, M. Kinetic study of the acid hydrolysis of sugar cane bagasse. Journal of Food Engineering, v. 5, n. 4, p. 309- 318, 2002. 


\section{REA - Revista de estudos ambientais (Online) v.21, n. 1, p.46-55, jan./jun. 2019}

ALDRICH, J.H. Correlations Genuine and Spurious in Pearson and Yule. Statistical Science, v. 10, n. 4, p. 364-376, 1995.

ALVES, J.M. Paradigma técnico e co-geração de energia com bagaço de cana de açúcar em Goiás. In: ENCONTRO DE ENERGIA NO MEIO RURAL, 6. Campinas. Proceedings online, 2006. Disponível em: http://www.proceedings.scielo.br/scielo.php?script =sci_arttext\&pid=MSC0000000022006000200021 \&lng=en\&nrm=abn. Acesso em: 27 mar. 2018.

ASSOCIAÇÃO BRASILEIRA DE NORMAS TÉCNICAS. NBR 10.007: Resíduos sólidos Amostragem de resíduos sólidos. Rio de Janeiro: ABNT, 2004a.

ASSOCIAÇÃO BRASILEIRA DE NORMAS TÉCNICAS. NBR 10.006: Procedimento para obtenção de extrato solubilizado de resíduos sólidos. Rio de Janeiro: ABNT, 2004b.

ASSOCIAÇÃO BRASILEIRA DE NORMAS TÉCNICAS. NBR 10.004: Resíduos sólidos Classificação. Rio de Janeiro: ABNT, 2004c.

BARKOSKY, Richard R.; EINHELLIG, Frank A.; BUTLER, Jack L. Caffeic acid-induced changes in plant-water relationships and photosynthesis in leafy spurge Euphorbia esula. Journal of Chemical Ecology, v. 26, n. 9, p. 2095-2109, 2000.

BRASIL. Ministério da Agricultura, Pecuária e Abastecimento. Regras para análise de sementes I Ministério da Agricultura, Pecuária e Abastecimento. Secretaria de Defesa Agropecuária. - Brasília: Mapa/ACS. 399 p, 2009.

BRASIL. Ministério da Agricultura, Pecuária e Abastecimento. Safra de cana-de-açúcar deve chegar a 635 milhões de toneladas. 2018. Disponível http://www.agricultura.gov.br/noticias/safra-decana-de-acucar-deve-chegar-a-635-milhoes-detoneladas. Acesso em: 27 mar. 2018.

CARVALHO, G.G.P. de; PIRES, A.J.V.; VELOSO, C.M.; MAGALHÃES, A.F.; FREIRE, M.A.L.; SILVA, F.F. da; SILVA, R.R.; CARVALHO, B.M.A. de. Valor nutritivo do bagaço de cana-de-açúcar amonizado com quatro doses de ureia. Pesq. agropec. bras., Brasília, v.41, n.1, p.125-132, jan, 2006.

CAVALCANTE, L.F.; CORDEIRO, J.C.; NASCIMENTO, J.A.M.; CAVALCANTE, Í.H.L.; DIAS, T.J. Fontes e níveis da salinidade da água na formação de mudas de mamoeiro cv. Sunrise solo. Semina: Ciências Agrárias, v.31, p.12811290, 2011.

COSTA NETO, P.L.O. Estatística. São Paulo: Edgard Blücher. 264p, 1977.
DUTRA, T.R.; MASSAD, M.D.; SARMENTO, M.F.Q.; OLIVEIRA, J.C. de. Substratos alternativos e métodos de quebra de dormência para produção de mudas de canafístula. Revista Ceres, Viçosa, v. 60, n.1, p. 72-78, 2013.

FAPESP (Fundação de Amparo e Pesquisa do Estado de São Paulo). Propriedades do bagaço da cana-de-açúcar. Revista Pesquisa FAPESP, edição 30, abril, 1998.

FARIA, T.M.; GOMES JUNIOR, F.G.; SA, M.E. de; CASSIOLATO, A.M.R. Efeitos alelopáticos de extratos vegetais na germinação, colonização micorrízica e crescimento inicial de milho, soja e feijão. Rev. Bras. Ciênc. Solo [online]. 2009, v.33, n.6, p.1625-1633. Disponível em: http://www.scielo.br/scielo.php?script=sci_arttext\& pid $=S 0100$

06832009000600011\&lng=en\&nrm=iso.

FENGEL, D.; WEGENER, G. Wood Chemistry, Ultra structure, Reactions. Berlin: Walter de Gruyter, 613p, 1989.

FRANCO, H.Á.; MARTINS, G.M. de O.; MUSSEL, Y.L.; MORENO, S.C.; THODE FILHO, S.; MARQUES, M.R. da C. Ecotoxicidade de Lixiviado de Aterro Sanitário na Germinação de Sementes de Alface (Lactuca sativa L.) e Pepino (Cucumis sativus L.). Revista de Estudos Ambientais, v. 19, n. 1, p. 36-43, 2017.

FUJII Y; HIRADATE S. 2007. Allelopathy: new concepts \& methodology. Enfield: Science Publishers, 382p.

GEORGIEV, V.; ANANGA, A.; TSOLOVA, V. Recent advances and uses of grape flavonoids as nutraceuticals. Nutrients. v.6, n. 1, p. 391-415, 2014.

LARCHER, W. Ecofisiologia Vegetal. São Carlos, editora RIMA. São Paulo, 529p, 2000.

MEDEIROS, R.S. Efeito da substituição do bagaço de cana-de-açúcar auto-hidrolisado por sorgo na fermentação ruminal em bovinos, digestibilidade in vitro em ovinos e desempenho animal em bovino em acabamento. Dissertação (Mestrado em Ciência Animal e Pastagem) - Escola Superior de Agricultura "Luiz de Queiroz", Universidade de São Paulo, Piracicaba, 1992.

MILLER, J.C.; MILLER, J.N. Statistics for analytical chemistry. 3. ed. Chichester: Ellis Horwood, 233p, 1993.

MOLINA, G.; SUZART, C.A.G.; BERGARA, S.; QUEIROZ, T.; DAISSUKE, M.; MORETTI, R.H. Caracterização de cultivares de cana-de-açúcar (Saccharum SSP.) para a produção de caldo de cana: pH e acidez titulável. In: XXI Congresso Brasileiro de Ciências e Tecnologia de Alimentos, 2007a. Belo Horizonte. 


\section{REA - Revista de estudos ambientais (Online) v.21, n. 1, p.46-55, jan./jun. 2019}

MOLINA, G.; SUZART, C.A.G.; BERGARA, S.; QUEIROZ, T.; DAISSUKE, M.; MORETTI, R.H. Caracterização de cultivares de cana-de-açúcar (Saccharum SSP.) para a produção de caldo de cana: Rendimento de caldo e valor de brix. In: XXI Congresso Brasileiro de Ciências e Tecnologia de Alimentos, 2007b. Belo Horizonte.

MOSIER, N.; WYMAN, C.; DALE, B.; ELANDER, R.; LEE, Y.Y.; LADISCH, M. Features of promising technologies for treatment of lignocellulosic biomass. Bioresource Technology, v. 96, p. 673686, 2005.

MURTA, R.M., CHAVES, M.A.; PIRES, A.J.V.; VELOSO, C.M.; SILVA, F.F. da; NETO, A.L.R.; FILHO, A.E.F.; SANTOS, P.E.F. dos. Desempenho e digestibilidade aparente dos nutrientes em ovinos alimentados com dietas contendo bagaço de cana-de-açúcar tratado com óxido de cálcio. R. Bras. Zootec., v.40, n.6, p.1325-1332, 2011.

OLIVEIRA, A.K.M.; PEREIRA, K.C.L.; MULLER, J.A.I.; MATIAS, R. Análise fitoquímica e potencial alelopático das cascas de Pouteria ramiflora na germinação de alface. Horticultura Brasileira, v. 32, p. 41-47, 2014.

\section{ORGANIZATION FOR ECONOMIC} COOPERATION and DEVELOPMENT - OECD. Terrestrial Plant Test: 208: Seedling Emergence and Seedling Growth Test. Guideline for the Testing of Chemicals Proposal for Updating Guideline 208, 2003.

PANDEY, A.; SOCCOL, C.R.; NIGAM, P.; BRAND, D.; MOHAN, R.E.; ROUSSOS, S. Biotechnological potential of coffee pulp and coffee husk for bioprocesses. Biochemical Engineering Journal, v. 6, n. 2, p. 153-162, 2000.

RIBEIRO, M.R.; BARROS, M.F.C.; FREIRE, M.B.G.S. Química dos solos salinos e sódicos. In: MELO, V. F.; ALLEONI, L. R. F. (Ed.). Química e mineralogia do solo, 1. ed. Viçosa, MG: SBCS, p.449-484, 2009.

RONCO, A.; BÁEZ, M.C.D.; GRANADOS, Y.P. Ensayos Toxicológicos y Métodos de Evaluación de Calidad de Águas - Estandarización, Intercalibración, Resultados y Aplicaciones; Morales, G. C., ed.; Centro Internacional de Investigaciones para el Desarrollo: Ottawa, cap. 1, 2004.
SILVA, C.D. da; COSTA, L.M. da; MATOS, A.T. de; CECON, P.R.; SILVA, D.D. Vermicompostagem de lodo de esgoto urbano e bagaço de cana-de-açúcar. R. Bras. Eng. Agríc. Ambiental, Campina Grande, v.6, n.3, p.487-491, 2002.

SILVA, V.L.M.M.; GOMES, W.C.; ALSINA, O.L.S. Utilização do bagaço de cana de açúcar como biomassa adsorvente na adsorção de poluentes orgânicos. Revista Eletrônica de Materiais e Processos. v.2, p. $27-32,2007$.

SIMÕES, C.M. de O.; SPITZER, V. Óleos essenciais. In: SIMÕES, C.M. de O.; SCHENKEL, E.P.; GOSMANN, G.; MELLO, J.C.P. de; MENTZ, L.A.; PETROVICK, P. (Org.). Farmacognosia: da planta ao medicamento. Florianópolis: Editora da UFSC. p.397-425, 1999.

SOBRERO, M.C.; RONCO, A. Ensayo de toxicidad aguda con semillas de lechuga (Lactuca sativa L.). In: Ensayos toxicológicos y métodos de evaluación de calidad de aguas. Ottawa, Canadá, IDRC/IMTA. Ed., v. 4, p. 71-79, 2004.

SOUZA, C.L.M. de; MORAIS, V. de; SILVA, E.R. da; LOPES, H.M.; TOZANI, R.T.; PARRAGA, M.S.; CARVALHO, G.J.A. de. Efeito inibidor dos extratos hidroalcóolicos de coberturas mortas sobre a germinação de sementes de Cenoura e Alface. Planta Daninha, v. 17, n. 2, 1999.

SOUZA, Z.J. de; AZEVEDO, P.F. de. Geração de energia elétrica excedente no setor sucroalcooleiro: um estudo a partir das usinas paulistas. Rev. Econ. Sociol. Rural, Brasília, v. 44, n. 2, p. 179-199, $2006 . \quad$ Disponível em: http://www.scielo.br/scielo.php?script=sci_arttext\& pid $=$ S0103-

20032006000200002\&lng=en\&nrm=iso. Acesso em: 27 mar. 2018.

SUN, J.X.; SUN, X.F.; ZHAO, H.; SUN, R.C. Isolation and characterization of cellulose from sugarcane bagasse. Polymer Degradation and Stability, v. 84, p. 331-339, 2004.

TAIZ, L.; ZEIGER, E.; MOLLER, I.M.; MURPHY, A. Fisiologia e desenvolvimento vegetal. 6. ed.Porto Alegre: Artmed. 888 p, 2017.

UNITED STATES ENVIRONMENTAL PROTECTION AGENCY - USEPA. Seed Germination / Root Elongation Toxicity Tests. Ecological Effects, Tests Guidelines, 1996. 